\title{
Information Technology Team Projects in Higher Education: An International Viewpoint
}

\author{
Kathy Lynch \\ University of the Sunshine \\ Coast, Queensland, Australia
}

kathy.lynch@usc.edu.au

\author{
Aleksej Heinze \\ University of Salford, Salford, \\ United Kingdom
}

a.heinze@salford.ac.uk

\author{
Elsje Scott \\ University of Cape Town, South Africa
}

elsje.scott@uct.ac.za

\section{Executive Summary}

It is common to find final or near final year undergraduate Information Technology students undertaking a substantial development project; a project where the students have the opportunity to be fully involved in the analysis, design, and development of an information technology service or product. This involvement has been catalyzed and prepared for during their previous studies where the students have been told and shown how to develop similar systems. It is the belief that only through this 'real' project do they get the chance to experience something similar to what is expected of them when they embark on their chosen profession; that is, as an information technology professional.

The high value of 'near real life' educational experience is recognized by many universities across the globe. The aim of this paper is to present examples from three countries - Australia, United Kingdom and South Africa, of the delivery of these team, capstone or industrial experience projects; their curricula and management processes. Academics from institutions in each of the countries share experiences, challenges and pitfalls encountered during the delivery of these information technology projects within their institutions. An overview of each institution's strategies is provided and highlights specific issues such as the selection of projects, allocation of teams to projects, legal requirements, assessment methods, challenges and benefits.

The pedagogies presented here are not exhaustive; however, the three institutions do have in common the implementation of a combination of constructivism with a community of practice approach in delivering the project unit. The three universities recognize the need for industrial

Material published as part of this publication, either on-line or in print, is copyrighted by the Informing Science Institute. Permission to make digital or paper copy of part or all of these works for personal or classroom use is granted without fee provided that the copies are not made or distributed for profit or commercial advantage AND that copies 1) bear this notice in full and 2) give the full citation on the first page. It is permissible to abstract these works so long as credit is given. To copy in all other cases or to republish or to post on a server or to redistribute to lists requires specific permission and payment of a fee. Contact Publisher@InformingScience.org to request redistribution permission. experience and learning of applied skills, and therefore make these projects a compulsory part of the curriculum. The projects tend to be real life business problems which are solved over a period of two semesters, and in the case of Cape Town it could be two consecutive years of two semesters each. These projects tend to involve practical development (for example databases and web sites). The process of project-to-team allocation is generally similar in all cases. 
Despite their differences, team work related problems are quite similar in all three cases presented, and seem to appear as a result of team work complexity, and the number of stakeholders involved. The intention of this paper is not to propose solutions to these problems (as these would be context dependent), but to draw the attention to the main problem categories for similar schemes, these are;

- project selection,

- management of students,

- management of academic staff,

- student team motivation,

- equality and diversity,

- passengers, and

- assessment.

Furthermore, it is not the intention of the authors to portray one approach as better than another, however, the approaches are representative of how team projects are being delivered across the globe, and in particular, in the contributing institutions.

It is hoped that the assimilation and dissemination of information regarding the various approaches presented will nurture further discussion, and open communication across the globe with the view to enhancing the teaching and learning experience of such projects.

Keywords: capstone projects, team projects, Information Technology, education, information systems.

\section{Background}

The earlier work of educational research was based on the teaching of associationist (Herbart, 1776-1841) and functionalist (Dewey, 1859-1952) theory (see Clark, 1999 for an overview of these theorists and their theories). Associations were based on the early beliefs that ideas were similar to real life. It was thought that new ideas would therefore create new paths in our brains. Herbart (1982) believed that if an idea was to be entrenched in someone's mind it would have to be related to similar ideas. A learner would therefore be more interested in ideas that they are already relatively familiar with, thus a teacher has to be aware of this and utilize it for teaching. This resulted in the five steps that defined teaching from Herbart's point of view: Preparation, Presentation, Association, Generalization and Application (Beck, 1965, p. 98). The first step would prepare students by drawing out any issue related to the topic to be studied. The presentation step would explain the new topic. Herbart suggested using concrete examples to explain the theory or a concept in question. Association would connect the already known with the newly learned with the differences and similarities highlighted. In the generalization section students are asked to consider the larger picture and use these ideas in other subjects. The final, application step, gives students the opportunity to apply the learned theory in practice, and appreciate new experiences.

Herbart's views were criticized by John Dewey, who observed that all work in a Herbartian class was teacher-and-subject-centered, in which case, students were only concerned with learning. Dewey on the other hand was of the opinion that students should learn problem solving rather than remembering and reciting (Beck, 1965, p. 100). Dewey echoed Darwin's (1809-1882) evolution principles and related evolution to an individual's learning. Dewey's view of the mind was that it is driven by the need for problem solving, rather than the association of already known facts as proposed by Herbart. To counteract Herbart's beliefs Dewey proposed his own five steps for teachers so that they could engage students in problem solving: Dewey's five stages are ech- 
oed in the stages followed in subjects that have team projects; for example; finding a business problem, determining the requirements; building and testing the solution and finally by implementing the completed product. Regardless of the theorist, team projects, and in particular IT capstone team projects allow for learning behaviors that cannot be realized in an individual learning environment.

The practical skills obtained during team projects are also one of the key benefits sought in team projects, and this was identified by Confucius $(551$ - 479 BC) - a long time before Dewey

"Tell me, and I will forget. Show me, and I may remember. Involve me, and I will understand".

Herbart and Dewey have identified some of the extremes in Higher Education - one focusing on teaching and the other on student learning. Since then a number of other theories have emerged, and some of the more influential work is evident in the Constructivist movement (Vygotsky, 1962) and more recently in Communities of Practice (Wenger, 1998). Both these movements emphasize group involvement, and learning from social interaction.

Within the IT arena, these projects are given one of many names: Industrial Experience project, Team project, or capstone unit/course/subject. A capstone course forms the culmination of many learning experiences students encounter during their academic careers. Moore (2005) reports that a capstone course serves as "an instrument of evaluation in all three modalities of learning". Capstone courses are designed to assess cognitive, affective and psychomotor learning in a studentcentered and student-directed manner which requires the command, analysis and synthesis of knowledge and skills (Moore, 2005).

Team projects engage students in an Action Learning Cycle, a cycle that promotes continuous planning, reflection, observation and action amongst participants (Bruce, 1997). This supports the psychomotor learning mentioned by Moore (2005) as an ongoing refinement process.

To successfully maintain this on-going refinement process, collaboration amongst universities on different continents can play an important role. To this end, an international viewpoint has been adopted for this study to enable a broad exploration of the differences and commonalities across the delivery of capstone IT team projects. Furthermore, an international perspective raises the opportunity to compare and contrast the group work element in team projects, facilitate information dissemination, and encourage future collaboration. The three international perspectives reviewed are from Australia, United Kingdom and South Africa. Each of these countries has numerous undergraduate Information Technology programs that offer capstone projects as an optional or as a mandatory course.

\section{Australia}

This first example of a course in which team projects are used as a means to prepare IT students for the industry they will face is from Monash University, Melbourne Australia. The three year full time degree program that is exemplified here is delivered in the Bachelor of Information Systems/Bachelor of Computing.

\section{Unit title, duration}

Third year Industrial Experience Project (IE studio). The duration of the project unit is commonly two semesters; however there is an accelerated version that runs for one semester and is worth the same 'degree' points as the two semester version of the unit. The IE unit is worth 12 credit points which equates to approximately $9 \%$ of the course and is compulsory for all final year students. 


\section{Synopsis of the project unit}

Final year students are given the opportunity to apply the knowledge and skills they have gained throughout their course, and develop of a computer-based system for a real world client. Students work in groups to design, develop and deliver an information system. During this process they learn to manage the project through all its development stages, communicate effectively with project stakeholders, develop project documentation to a professional standard, present their project work to academics, the client, and industry personnel.

\section{Unit background}

The students attend four hours a week of classes of which one hour is a professional development seminar, the other three hours are dedicated to their project work: The accelerated unit has the one hour professional development seminar, and one six hour 'studio' class each week. Each class has between four and six projects, with 4-6 students in each project team. A studio-based teaching and learning model is used to deliver the unit (see Carbone, Lynch, Arnott and Jamieson, 2000 for an overview of this model; and Lynch, Goold and Blain, 2004 for a comparison with traditional models). There is one academic and one tutor allocated to each 'studio' class, 2 and 3 hours respectively (and for the accelerated unit, 4 and 6 hours respectively).

\section{Types and selection of projects}

Each project is allocated to one team only, and a client may have more than one project. The one common feature of projects is that they are all real projects, that is each project has a client who requires a 'system' to be designed and developed. A call for expression of interest in participating in the student project program is sent out to local councils, previous clients, faculty members, friends, and colleagues. Prospective clients are sent a project profile, this requires them to fill in contact details, company profile, 10 lines regarding their requirements, information about any special hardware/software constraints or requests, known absences, and the preferred end date of the project (4 or 8 month project).

The project profiles are read by the Project Coordinator to determine their suitability for the program.

\section{Legal requirements}

Once a client and project are accepted by the Project Coordinator, a Memorandum of Understanding is sent to the client for signing. Once the project has commenced a number of legal documents are required by the University. These cover copyright, intellectual property, personal liability, insurance (student), and schedule. Clients may require additional documents to be signed by the students or the University representative, for example confidentiality contracts.

\section{Allocation of projects to students}

The project profiles are made available to the project teams, who then nominate five projects (prioritized) that they are interested in pursuing. Each team submit their preferences together with a short summary as to why they are interested in doing a particular project, and a team skills audit. The IE management team (composed of academics), allocate projects according to a team's expression of interest, and team skills.

\section{Assessment}

Each IE studio class has one academic and one tutor, with up to six project teams. The tutor is responsible for marking most of the deliverables according to marking guidelines developed by the academic team. There are group (80\%) and individual (20\%) assessment tasks. The group 
deliverables are related to the development process and the final product, and the individual tasks are the student's reflection of their progress, challenges, progress and aspirations. The academics mark the student's individual reflective pieces, and chair the final Project Implementation Review meeting.

As no two projects are the same, the specifics for the project assessment are not identical, however, there are several common themes: these include project definition, standards, risk analysis, project management, and post implementation review. All teams are given the option of submitting a peer assessment review for each of their team members.

Furthermore, client feedback is sought at the conclusion of the project. This feedback does not have a mark associated with it, but if the feedback has no resemblance to the final mark for the group deliverables for a given project, then both the feedback and the deliverables are reviewed and the marks may be adjusted.

\section{Main challenges}

Obtaining suitable projects. The call for projects is always fraught with uncertainty, and most often all projects are initially signed. It is only after the first call for expression of interest, that it is known what type of projects the students are not interested in. Then the details are clarified between the project team and a client - the change from the original brief project specification is common, but at times this change brings about a project that is not totally suitable.

Setting of common deliverables for disparate projects. Not all projects follow the same development life cycle and not all projects are development projects - some are specifications, others are maintenance or customization, often they may use different operating systems, different hardware, and maybe networked or standalone; therefore setting one common set of deliverables is difficult.

Allocation of projects (when there are more than 20 projects). Project teams need to put forward an Expression of Interest (EOI) in priority order; however not all teams end up with any of their preferences. The actual allocation of the projects is subjective as the allocation team has only the EOI forms and the skills analysis to work from.

Team motivation in the early stages. It is common to see that during the year long projects there is often lack of motivation in the early stages by the 'programmers and testers' in the team. Generally, the team members feel that they have plenty of time to complete their project, and are therefore quite tardy in the early stages (and run out of time in the later stages) of the project. Team motivation is not an issue in the one semester unit as these teams must work at double pace relative to that of the full year unit.

Life/project balance in the later stages. Although the project is only $9 \%$ of the total points for the degree program, students spend large amounts of time finishing off the project. Often teams become dysfunctional due to the pressure - (or they thrive on the pressure). Some students spend large amounts of time on their IE work, with other subjects consequently suffering. The environment available for the students to work is accessible 24/7, and therefore students have a tendency to 'live' in the studio precinct instead of going home.

Equality within/out teams. Not all teams are equal - in technical skills or in communicating. Although an individual and team skills audit are conducted, and team members are given an opportunity to move prior to the allocation of a project, there is commonly a team that, in the first instance, does not have the technical skills required to develop the final system. The bigger issue is the mix of personalities within teams - some teams run smoothly, other teams have members that never overcome their difference enough to be able to produce a quality result. 'Sight seeing' or 'project passenger' is another equity issue. It often fixes itself around the middle of the project, 
however, if it hasn't, team members become disgruntled and the project suffers either by sections of the requirements not being completed to the standards required, or by some team members being overworked.

Recalcitrant clients. All clients are enthusiastic at the start of the projects, but as time progresses, some of their enthusiasm is dramatically reduced, and therefore can hinder the students' ability to complete the unit's objectives. Rarely, though not uncommon, a project is cancelled due to an uncooperative client (and the team is allocated another project).

Management of the teaching team. In 2006 there were 15 faculty involved in supervising the project teams. Of these eight were academic: It is no easy feat trying to get eight academics to be at the same place for a meeting, to agree on assessment requirements, and to moderate between the multiple classes, projects and tutors.

\section{Benefits}

Without a doubt, students state that the IE studio unit is the most rewarding part of their undergraduate program. This is due to the real projects, the mixing with industry people, the professional manner in which the students are treated by academics, tutors and clients. Client events run throughout the program have been a great success, as they have given the students an opportunity to develop their communication skills in a professional setting. The first such event is a 'Wine and Cheese' and encourages the students mingled with all clients; it is held early on in the project's development. The final event is a public Expo, where clients, industry personal, potential employers, faculty and other students attend. One recent graduate reports;

"I am able to do this work [database development], make comment at meetings and be useful because of what we learnt in studio"

\section{Unit web site}

The following website for Industrial Experience Studio project provides some further information: http://www.infotech.monash.edu.au/units/fit3015/study/

\section{United Kingdom}

The second example of our international review is the University of Salford in Salford, England. Salford Business School offers Bachelor degrees in Business Information Systems, in Business Information Technology and in eCommerce. Generally these are 3 year full time programs, and each of these allows students to take out an optional Industrial Placement year, giving students the opportunity to gain even more Professional Experience.

\section{Unit title, duration}

The name of the module is Team Project, which involves students from all levels: first year, second year and the final year.

The duration of team projects is generally two semesters, starting in September and finishing in May the following year. There are exceptions to the general rule, with some projects that have been running for several years and some that finished after just one semester.

\section{Synopsis of the project unit}

Team projects allow students to develop team working skills in near "real life" settings. Working in teams that are managed by students and facilitated by academic tutors, students can apply project management and other subject related material to the individual project. In particular the col- 
laboration between years and with real clients provides enriching personal development opportunities for everyone involved.

\section{Unit background}

Since 1986 Team Projects have been an integral part of degrees in the Information Systems Institute now a subject group within the Salford Business School. In multi-year, multi-skilled teams of about 12 students with roughly equal numbers of students at first, second and final year; students work on real life, open-ended projects provided by organizations (Project Clients). This means that students when they graduate would have three team projects as part of their learning experience.

Overall students spend nearly $25 \%$ of their degree time ( 70 credits out of 360 ) by being engaged in team projects; hence they play a major part in their degree classification.

As depicted in Table 1, student roles within the team project vary. In the first semester students from the first year take on the role of "apprentices". They are asked to observe the second and the final year students and are not marked for their contribution. In the second semester they are marked for their work and it contributes 10 credits towards their year average.

Second year students are assessed in both semesters and receive 20 credits per semester. Usually one of the second year students is assigned to be a deputy team leader, and becomes the team leader in the second semester. The team leader in the first semester is a final year student who has to step down in the second semester. The final year students are assessed in the first semester and have the role of consultants in the second; their contribution is weighted at 20 credits.

Table 1: Team project roles outlined by year and semester

\begin{tabular}{|l|l|l|l|}
\hline Year: & First & Second & Final \\
\hline $1^{\text {st }}$ Semester & “Apprentice” & Full team member & Full team member \\
\hline $2^{\text {nd }}$ Semester & Full team member & Full team member & "Consultant" \\
\hline
\end{tabular}

Each week on two specific afternoons there is an allocated slot for students from all years who take part in the team projects. In this slot facilities such as computer laboratories and meeting rooms are available for students to use. Since the academic tutor assigned to a team is also the personal tutor for the individual team members, this provides a good informal environment to get to know students and provide help where possible.

\section{Types and selection of projects}

Projects might lead to the development of a piece of software or may be more business-oriented, for example a piece of evaluative research or recommendations for a new organizational strategy. The team project clients also vary from year to year; these can be a charity or a major international company.

Clients are invited to fill in a Team Project Request form, which asks them briefly their contact details and concise project overview. Each project is evaluated by the Project Manager, who distributes these requests to academic tutors and team leaders for comments, based on this feedback and other assessment criteria the projects are approved or rejected. 


\section{Allocation of projects to students}

Clients can have several projects but only one project is allocated per team at any one time. Students are allocated to projects based on their module marks for the first and second year and in the case of first year or direct entry students, they are allocated randomly to a project. Where possible, each team would be allocated at least one student coming back from their Industrial Placement year, since these students bring real life experience and useful skills that are of benefit to the teams. There is some level of consultation between team leaders and team deputies who have some influence on what kind of project they would prefer.

\section{Legal requirements}

Clients are made aware that projects are primarily for educational purposes and therefore the teams are not liable if a project does not produce desirable outcomes. There are no formal documents that are required to be signed by either party involved. Generally if a project involves work on confidential systems such as the Police etc, team members might have to go through security checks to comply with the client's risk management processes.

\section{Assessment}

Assessment is done primarily by the team tutor, who facilitates the team from the beginning to the end of the project. All project marks are reviewed by another academic and where necessary marks are adjusted.

Each student is allocated an individual mark and a team mark. The individual marks are based on the individual reports and the individual's contribution to the project. This contribution is informed by the team leader and team deputy who report on individual team members and on the tutor's personal observation. Students are required to complete a peer evaluation form to rate their colleagues and provide comments on the individual contributions. This is used again to inform the tutor in their assessment process.

The overall team project marks are based on two main criteria - the process and the product. Since all projects vary in complexity and have their own challenges, it is difficult to set specific criteria for assessment descriptors, since the product can be a technical artifact or a consultancy report. The process is equally divided into Scholarship and Organization categories. Scholarship is concerned with issues such as Independence of work conducted, research and linking of knowledge from other modules. Organization is concerned with project scope, initial appraisal, planning, tracking, communication and team work in general. The product is more open and is based on the academic assessment of the quality of work produced and the feedback from the client.

Generally students have to produce the following three reports: Individual, Client and Team Academic report. They demonstrate their developments in a formal presentation in the first semester and an exhibition at the end of the second semester - end of the project.

\section{Main challenges}

In the summer of 2006 a Team Projects review highlighted a number of issues with team projects, some already known and some new. The seven main problem areas are discussed below:

Assessment. A process-oriented assessment approach (Jones \& McMaster, 2004, p. 379) together with an agile development approach with an emphasis of a "Product" that is as important as the process. Once a team mark has been agreed upon, further challenges are posed by the individual marks. To help with the tracking of individual contributions, a detailed deliverables chart is a compulsory part of each team project report. Peer assessment is used, though there is some evi- 
dence to suggest that the peer-assessment is sometimes misused by students and may be used as a weapon against others. 'If you don't like me - I will mark you down' attitude had caused some distrust. This is mitigated by the tutors' observations in order to fairly assess individual contributions.

Passengers. The problem of passengers is one of the main concerns for the students, the general feeling is reflected by the following quote (Heinze \& Cooper, 2006):

"Generally you tend to have 2 sorts of people in a project team. People who do the work and those who don't. Those who don't generally only turn up towards the end of the project only to cause more hassle (since they require being brought up to speed)."

It is expected that students have different attitudes to project work. Some are very keen on getting the work done and getting a good mark. Other students adopt the strategy of doing the minimum work to achieve a pass mark, and others fall somewhere in between.

It is only worth being a passenger if you can get away with it easily. A number of mechanisms to prevent or deter passenger behavior have already been implemented. All students are aware of this or they only become aware of it once they have failed a module.

The individual and group mark weighting that contributes to the final module mark has been adjusted from $50 / 50$ to $70 / 30$. Now the individual mark counts $70 \%$ towards the final group mark.

A minimum individual mark of $40 \%$ is required for students to benefit from a share of the overall team mark. This means that if a student was very poor and gained an individual mark of 23, this is the mark that he or she will retain as their total team project mark. If a student gained 40 marks or over as an individual, his or her overall mark takes into account the team mark.

Student Motivation. An issue that is closely linked with the passenger problem is that of student motivation. At this stage it is important to note that the assessment or the mark that students get is becoming the prime motivator to engage with a module. If students know that they can get away with doing nothing and still get a good mark, they are unlikely to be motivated to perform well. At this stage peer assessment and tutor involvement gain importance. Furthermore, the nature of the project can be a powerful motivator (Heinze and Cooper, 2006).

Generally, the following issues emerge as motivators to get students enthusiastic about team projects:

- Assessment that takes into account the individual contribution

- Projects that can be practically implemented in real life

- Major company clients - where students can potentially get a placement or a job

- Projects that have high expectations of students

Tutor involvement. Generally, there are two extremes that are emerging, the first one is where the tutors don't engage with the students and the second is where students are constrained by the tutor, who is very much engaged with the team. It is generally agreed that the academic tutor is there as a tutor and not as a team leader. The "working" tutoring pattern seems to be where team tutoring is given priority in the first weeks of the project while negotiating the project scope, and then again at the time of the mid semester review and assessment hand in.

There also appears to be an issue relating to the expertise and experience of tutors. This relates both to their technical and project management expertise in advising the team, and to their mentoring expertise in supporting the team. 


\section{Benefits}

Multi Year Team Projects is a unique scheme that provides a platform of extremes. Team learning has tremendous potential to provide an exciting learning opportunity for students as well as staff. The main problem lies in the implementation and execution of the team related processes, the key stakeholders which are staff and students.

It is difficult to quantify the benefits of team projects since they are realized when students leave the course, and there is only anecdotal evidence to suggest that students spend a lot of time in their job interviews discussing team projects, and that this makes our students stand out (Jones \& McMaster, 2004).

Both staff and students do recognize positive aspects; the following quotes from students illustrate some of these (Heinze \& Cooper, 2006):

"So many benefits, such as improving communication skills, relationship with other students, experience from different students for example: students from final years share their experiences with the second and first years." (2nd year student)

"Provides early insight into what is involved to manage a project. Provides opportunities to build interpersonal, communication skills and leverage existing knowledge with peers of different academic backgrounds. " (3rd year student)

\section{Web site}

The following website for Team Projects provides some further information: http://www.business.salford.ac.uk/teamprojects/is/

\section{South Africa}

The third example of delivering IT team projects is from Cape Town. Team projects form a core component of the Bachelor in Commerce (3 full years) and Bachelor in Business Science (4 full years) degrees, offered at the University of Cape Town (UCT).

\section{Unit title, duration}

The $3^{\text {rd }}$ year team project course, with a duration of approximately two semesters, is called Project Management: Theory and Implementation. The major skills transfer, analysis and design, happen during the first semester, whereas the second semester is dedicated to building of the system. The $4^{\text {th }}$ year course repeats the systems development project as a major deliverable over two semesters. The $4^{\text {th }}$ year course is made up of final year Business Science and post graduate Bachelor in Commerce students.

\section{Synopsis of the project unit}

A main focus of the project unit is to enhance the students' knowledge of project management. This involves the understanding of the project lifecycle and the difficulties of scoping and controlling projects. A project planning framework is used to assist in scheduling tasks and activities. Estimation techniques are applied to estimate effort, and a risk analysis is executed for every project.

During the course special attention is given to assist students in managing their project teams by effectively administering team roles and by resolving team conflict. Peer assessment practices are applied to final grades to eliminate discrepancies among contributions of respective team members. 
The project unit also focuses on the consolidation of theoretical knowledge and skills in systems development, and adheres to Software Engineering Institute (SEI) guidelines and principles to improve software engineering practices. At the end of every academic year, an EXPO is held, where all projects are showcased to industry and secondary school students to promote Information Systems.

\section{Unit background}

At UCT the development thread of the IS major runs over a period of three or in some cases four years. During this period students are guided to follow Cockburn's (2002) model of Learn, Detach and Transcend towards maturity in systems development practices. Most faculty members are involved in the $3^{\text {rd }}$ year course and act as project managers (PMs) to one or two project teams. The course coordinator acts as facilitator, resolves conflict and oversees all projects. Although faculty members are available to guide project teams and assess project deliverables, every team has a team leader and is expected to manage and take responsibility for their own projects.

The $3^{\text {rd }}$ year teams adhere to a rigorous schedule of activities like skills transfer sessions, regular meetings and submission dates of deliverables. The project runs in parallel with other course activities like lectures, workshops and tutorials. Most of these activities only happen during the first semester. Project management and other topics (4 lectures per week) and tutorials (1 two hour session per week) are aligned with project deliverables. A prototype is developed during coding workshops (4 hours per week) to familiarize students with design patterns and good programming principles. The second semester is mostly dedicated to development, with no formal lectures. All student teams use the same development environment and implementation platform, and they use Microsoft Project Server environment to assist in project planning and collaboration. Templates are used extensively for most documents and procedures in support of standardization.

The $4^{\text {th }}$ year project runs in parallel with lectures, seminars and an empirical research project. A larger degree of flexibility is allowed in terms of the application theme, the development environment and the implementation platform. Given that the $4^{\text {th }}$ year students are more experienced and mature than the $3^{\text {rd }}$ year IS majors, an iterative development approach was introduced for the first time in 2006. They have less external rigor and fewer deliverables during the course of the project and faculty members do not act as project managers.

The $4^{\text {th }}$ year students act as tutors during the $3^{\text {rd }}$ year workshops and occupy regular hot seats during the development phase of the $3^{\text {rd }}$ year projects. They also assess a "mock" presentation for the $3^{\text {rd }}$ year teams, two weeks before the final hand-in date, providing valuable feedback that allows $3^{\text {rd }}$ years to enhance their products.

\section{Types and selection of projects}

At the beginning of every year the IS major students are provided with a project brief that describes a generic business opportunity/situation of concern that will represent the common theme for the year. It also lists the main functionality required for such a system. Projects are either fully web-based or incorporate a component that is web-based. The theme chosen allows for a wide variety of projects in the business sector, and challenges students to find a "best fit" to the generic specifications.

Requests from organizations in industry or government for systems to solve specific problems contribute to an initial pool of possible projects. The requirements for these projects are evaluated to ensure that they are suitable, of the correct scope and meet the right standard.

The $4^{\text {th }}$ year IS project is a carefully scoped real world project, and builds on the experience gained in the similar but smaller $3^{\text {rd }}$ year project. Unlike the $3^{\text {rd }}$ year students, these students have to identify a need in industry and translate this need efficiently and creatively into an automated 
computerized system. The focus is to incorporate complex business processes in an integrated, easy to maintain and easy to use system.

\section{Allocation of projects to students}

Students have the option to tender for available projects that are in line with the requirements provided. They may also find their own sponsor (client) in industry, with a business need that matches the generic specifications best. A sponsor's main responsibilities are to assist the team to gain a better understanding of the company's business processes. This information is used to establish the project requirements and scope.

Fourth year students have the first opportunity to tender for the available projects. Prospective sponsors take part in this selection process, and the successful teams are allocated to the respective projects. Third year students may submit tenders for the remaining projects.

The majority of student teams however, still find their own sponsors in industry. This often happens before the start of the academic year. The process of finding a suitable sponsor is seen to contribute to the rich learning experience of the project.

Although teams are mostly self-selected, a faculty member in the Department of Industrial Psychology facilitates and finalizes the team formation process (Scott \& Pollock, 2006). Student surveys filled out prior to the team selection process are used to assist the facilitator. In these surveys students are mainly required to list their strengths, weaknesses, skills and what they intend to contribute to the project and team. Once teams of 5 members are formed, a team contract is completed and signed by each member. On some occasions teams of 4 members are allowed. A team role document is also filled out specifying the respective roles of members of each team. Team members are allowed to swap roles, or to fulfill more than one role.

\section{Legal requirements}

A sponsor guide prepared by the legal section of the university describes the participation guidelines for all parties involved. This includes sections on the commitment by the participating organization, risks, compensation, ownership and rights in terms of intellectual property. A sponsor is required to submit a signed commitment form at the beginning of a project.

\section{Assessment}

A comprehensive assessment strategy is used in the $3^{\text {rd }}$ year course, implementing various instruments to accomplish formal summative assessment, formal continuous assessment and an informal formative assessment (Pellegrino, Chudowsky, \& Glaser, 2001; Shepard, 2000). Scoring rubrics constitute the main instrument in the assessments of the group projects and provide students with a clear understanding of the standards against which they will be measured (Scott \& Van der Merwe 2003). The continuous assessment strategy provides for several review points, feedback and opportunities for improvement throughout the year.

In the first half of the course the project planning and the analysis and design phases are completed, comprising 7 interim deliverables (4\%), and are marked by the respective project managers. Each of the deliverables incorporates:

- Software Development Deliverables

- Project Management Deliverables

- Quality Management Deliverables

The improved deliverables (which incorporate the feedback of the PMs) are collated into milestone deliverables $(10 \%)$ that constitute the business case; user requirements and system specifi- 
cation documents respectively. Specially designed rubrics are used to double mark these documents.

In the second half of the course (the build phase), it is expected that the students will keep their project plans updated. They provide weekly updates on team performance, team dynamics, new ideas, and their time management. In addition, every team member has to complete a timesheet on a weekly basis.

Each project sponsor completes two evaluation forms, one by mid year and the other one after the project is completed. These evaluations contribute $2 \%$ towards the total mark. Another $4 \%$ is obtained from coding workshops. A "mock" presentation, marked by $4^{\text {th }}$ year students two weeks before the hand-in date, provides valuable feedback on user-interfaces and functionality. This mark is included as part of the interim deliverables mark.

The final project hand-in (20\%) includes copies of the milestones, the test cases, user manual and the system. For the project and code presentation, rubrics are used. The project presentation is marked by a panel of faculty members, whilst the code is marked by the course coordinator. A code examination terminates the course and serves to increase the individual component of the course.

The project management section constitutes the other $40 \%$ of the course.

The $4^{\text {th }}$ year Systems Development (SD) mark comprises $20 \%$ of the year mark.

Since 2002 a peer assessment instrument has been developed and included in $3^{\text {rd }}$ and $4^{\text {th }}$ year, assisting in a more accurate assessment of individual contributions to team projects (Scott \& van der Merwe, 2003). The peer assessment may affect a team member's final mark.

\section{Main challenges}

Motivation: A major challenge of a capstone course is to maintain a high level of motivation while students are facing problems that closely emulate professional practice. Effective communication at all times is essential to encourage, motivate and to cultivate commitment,

Time management: Effective time management is one of the most difficult issues to be addressed in team projects. Meeting deadlines in team projects can become very demanding, and in many cases these projects consume most of the students' time, especially during the development phase. Careful guidance and mechanisms like Gantt charts and time sheets, help teams to balance their time between the project deliverables, demands of other courses and personal commitments. First time project teams tend to underestimate the extent of the project, and they are tempted procrastinate.

Passengers: Social loafing is a term used by Smith (2004) to identify students who under perform in project teams. Although every effort is made to discourage and eliminate social loafing, the phenomenon still occurs and is eminently the cause of serious conflict in teams. The work ethic of people differs and their reactions to stress and pressure vary vastly. Many students admit that working in groups can be very challenging and they often struggle to resolve conflict effectively.

The peer assessment instrument does not always provide the perfect solution to team problems. Where teams are divided into two camps their assessments can counteract one another and alternative mechanisms have to be found to resolve issues.

Equality and diversity: Different work ethics and work expectations of various people are often causes of serious group conflict. A diversity of skills and different cultural backgrounds are additional factors that might cause conflict if not properly controlled and monitored. 
Information Technology Team Projects in Higher Education

Course Overhead: The smooth running of team projects is a challenge to faculty, and requires commitment and dedication. Courses that involve team projects are usually strenuous, time consuming and include a vast amount of "behind the scenes" activities.

Suitable Projects: Collating the projects received from industry and coordinating an effective tendering process do not prove to be an easy feat. It is also necessary to find a effective way to evaluate the suitability and scope of projects obtained from industry and those the students find on their own.

\section{Benefits}

The IS 2002 Curriculum (Davis, Feinstein, Gorgone, Longenecker, \& Valacich, 2001) identifies a broad business and real world perspective, the development of strong analytical and critical thinking and the cultivation of effective communication and team skills as the three key areas that permeate every facet of the IS profession.

The team project provides an excellent vehicle to expose students to real world development, project management, life skills and tight deadlines. This exposure broadens the students' vision, stimulates deep learning and promotes excellence. Despite the immense tension and challenges, students are excited by the project and they thoroughly enjoy the experience, as indicated by comments in their course evaluations:

"The project has been the greatest learning curve in my university career; it is essential to IS and definitely resulted in personal growth, emotionally, psychologically and technically."

"A real world application of concepts. Course requires creativity, teamwork and problem solving. A nice change from parrot learning."

"A challenging course, but the experience of a lifetime"

An alumni student confirms the benefits of team projects as follows: "The dynamics of the university projects are exactly the same in many areas as this commercial one, right down to the interaction and attitudes of people in the team."

\section{Web site}

The following website provides more information on the capstone course: http://www.commerce.uct.ac.za/InformationSystems/Courses/INF3003W/

\section{Discussion}

Having presented the three cases of IT projects, the following section discusses some of the similarities and differences.

\section{Similarities}

The three universities recognize the need for industrial experience and learning of applied skills, and, therefore make these projects a compulsory part of the curriculum. The projects tend to be real life business problems solved over a period of two semesters, and in the case of Cape Town, the two semester project experience is repeated in the fourth year. These projects tend to involve practical development (for example databases and web sites). However, in the case of Salford Business School, some projects can be more oriented towards business documentation (for example the development of business strategies and feasibility studies). 
The process of project to team allocation is generally similar in all cases. To a varying degree, teams have the opportunity to influence the project selection, which gives teams a sense of ownership and to potentially influence their motivation to carry out a certain project.

Despite their differences, team work related problems are quite similar in all three cases presented. These seem to appear as a result of team work complexity, and the number of stakeholders involved. It is not the intention of the authors to propose solutions to these problems since these would be context dependent, but they want to draw the attention to the main problem categories:

- project selection,

- management of students,

- management of academic staff,

- student team motivation,

- equality and diversity,

- passengers, and

- assessment.

Coordinators of similar schemes could use the above categories for their risk management and/or mitigation processes.

\section{Differences}

The practical implementation of the project work differs. In the case of Monash University, student time commitment is at least four hours per week with studio sessions and seminars being attended by academic and tutoring staff.

Students involved in these team projects are in the case of Monash in their third year and in the case of Cape Town in their third and fourth years. In Salford, all years (first, second and final) of the program play a part. In the Cape Town example the students in their fourth year are repeating a team project over two semesters. During this iteration however, flexibility is encouraged and the focus is on creativity and innovation. Students use an agile approach with less deliverables and minimal scaffolding is provided.

The main differences are in the assessment, and in particular the weighting of team and individual marks. In the case of Monash, an $80 \%$ weighting is for group work, and $20 \%$ for individual work. In the case of Salford the weighting is heavier on the individual mark with $70 \%$ individual and $30 \%$ group work, whereas in Cape Town the split is 40/60, with the group work accounting for the $60 \%$ of the total mark.

Peer assessment review is utilized in all cases. This addresses one of the problems of passengers and the subjective opinions of individuals involved in assessing each other. Client feedback is used as moderation for team project work in all cases to a varying degree: in the case of Salford it is $25 \%$ of the team mark, and in the case of Cape Town it is $2 \%$ of the overall mark. In the case of Monash, client feedback is not directly incorporated into the assessment.

\section{Conclusion}

The student experience during an Information Technology Industrial Experience project, team project, or a capstone project encompasses not only the technical skills of the discipline, but, and more importantly, the social aspect of systems development. The team spirit and the associated problems that emerge from social interactions, and the ways that students manage to cope with 
them are some of the key benefits that outweigh problems encountered in such a learning experience.

It is difficult to simulate real life working conditions, but these kinds of projects bring education a step closer to the real world, and therefore prepare students for the IT professional environment they will encounter when they leave university. Unless students are able to solve real life problems rather then reproducing material provided to them in lectures and books, they are not going to be successful in the industry, where most problems are unique.

Some of the differences in the presented viewpoints appear in the actual process and the degree of real life that is offered. In case of Salford University it is the students responsibility to manage the project, the tutors are only there as facilitators. This is similar at Monash University, though here they have both an academic (or faculty) and a tutor watching or mentoring the students. On the other hand at the University of Cape Town it is the responsibility of the academic members of staff to manage the third year project. It is only in the fourth year, that the students are given the authority to manage their own projects. This issue brings numerous difficulties in case of Salford and Monash in relation to assessment, since it is only the students who have a true understanding of where the project is, and not the academic assessor, thus highlighting the difficulties discussed above, for example the identification of individual contributions.

We have gone a long way since the discussions of Dewey and Confucius but the actual pedagogy of learning is still relevant, although it might have been labeled and augmented by other thinkers who focused on constructivist and more recently on communities of practice ideas.

People are learning every day, and the main objectives of these projects are to prepare students for the industry of their choice, and to encourage life-long learning. A desired improvement in the quality and the readiness of these IT undergraduates can be achieved though examining the manner in which IT team projects are delivered across a number of nations. An exploration of the similarities and the differences is a way in which we, as academics, can share, discuss, manipulate and enhance the way we deliver IT team projects to the benefit of the students and the industries in which they will be employed.

Regardless of the delivery approach used, the project, or the assessment, anecdotally, the capstone project is the most valuable learning experience these students have generally encountered during their IT degree.

Through this initial investigation into how capstone projects are delivered by a number of institutions across the globe, collaboration has been strengthened between several researchers. This collaboration gives way to an opportunity for a comprehensive study to explore the learning experiences of the students - not so much as a comparison between pedagogies, but more as to what students achieve, their reflection on their development throughout the project, their readiness for the IT profession. Moreover, the collaboration between academics across international boundaries could lead to improved teaching practice through an examination of diversity, exchange of ideas and resources, and the development of strategies to overcome some of the challenges outlined in the paper.

\section{References}

Beck, R. H. (1965). A social history of education. London: Prentice Hall.

Bruce, C. (1997). Peer Review: A handbook. Queensland University of Technology.

Carbone, A., Lynch, K., Arnott, D., \& Jamieson, P. (2000). Introducing a studio-based learning environment into information technology. In proceedings of the Australian Society for Education Technology and the Higher Education Research and Development Society of Australia Conference: Flexible learning for a flexible society. (ASET/HERDSA) 2-5 July. Toowoomba, Queensland. 
Cockburn, A. (2002). Agile software development. Pearson Education, Inc.

Clark, D. (1999). History. Accessed November, 2006 from http://www.nwlink.com/ donclark/hrd/history/history2.html

Davis, G. B., Feinstein, D. L., Gorgone, J. T., Longenecker, Jr., H. E., \& Valacich, J. S. (2001). IS 2002: An update of the information systems model curriculum, Retrieved from http://www.spatial.maine.edu/SIEWEB/IS_ModelCurriculum.pdf

Jones, M. C. \& McMaster, T. (2004) Addressing commercial realism and academic issues in groupbased IS undergraduate project work. Journal of Information Systems Education, 15(4), 375 - 381.

Heinze A. \& Cooper, G. (2006). Team projects review 2006. University of Salford, Salford, UK (internal report).

Herbart, J.H. (1982). Pädagogische Schriften. Erster Band: Kleinere pädagogische Schriften. Ed. by Walter Asmus. Stuttgart.

Lynch, K., Goold, A \& Blain, J. (2004). Students' pedagogical preferences in the delivery of IT capstone courses. In Issues in Informing Science and Information Technology, 1, 431-442. Accessed July 2006, from http://articles.iisit.org/067lynch.pdf

Moore, R. C. (2005). The capstone course. In W. G. Christ (Ed.), Assessing media education: A resource for educators and administrators. Hillsdale, NJ: Erlbaum. Accessed November 2006 from http://users.etown.edu/m/moorerc/capstone.html

Pellegrino, J.W., Chudowsky, N. \& Glaser, R. (Eds), (2001). Knowing what students know: The science and design of educational assessment. Washington, D.C: The National Academic Press.

Scott, E. C. \& Pollock, M. (2006). Effectiveness of self-selected teams: A systems development project experience. Proceedings of the Informing Science \& IT Education Conference (InSITE2006), Manchester, UK. June 2006. Available at http://proceedings.informingscience.org/InSITE2006/IISITScot217.pdf

Scott, E. C. \& Van der Merwe, N. (2003). Using multiple approaches to assess student group projects. The Electronic Journal of Information Systems Evaluation (EJIS), 6(2), 177-186.

Shepard, L.A. (2000). The role of assessment in a learning culture. Educational Researcher, 29(7), 4-14.

Smith, D.C. (2004). Peer evaluations in information systems student project teams: Pitfalls and practice. SACLA Conference, South Africa, June 2004.

Vygotsky, L. (1962). Thought and language. Cambridge: MIT Press.

Wenger, E. (1998). Communities of practice: Learning meaning and identity. Cambridge: Cambridge University Press. 


\section{Biographies}

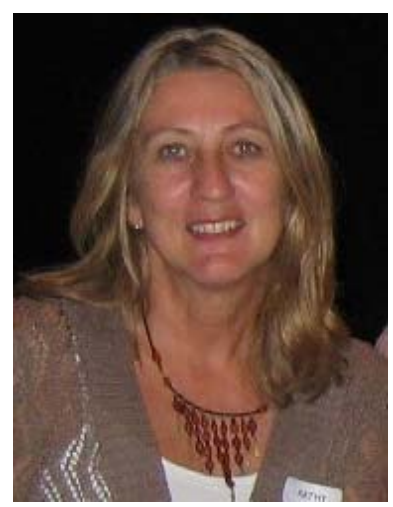

Dr Kathy Lynch is an Associate Professor, ICT Research and Development, at the University of the Sunshine Coast, Queensland, Australia (previously of Monash University, Melbourne). Her current research interests encompass collaborative work, enabling and emerging technologies, HCI, usability, and IS/ICT education. She has a Doctor of Philosophy (Education), together with numerous other qualifications in the disciplines of IT and Education. She is the Editor-in-Chief of the Interdisciplinary Journal of Information, Knowledge, and Management (IJIKM).

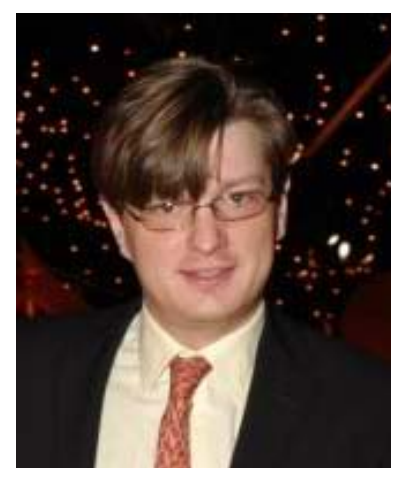

Aleksej Heinze is a lecturer in the Salford Business School, University of Salford. His current research interests are concerned with the practice of Blended Learning in higher education and the general application of information technology for educational purposes. He is a member of the British Computer Society and the UK Higher Education Academy.

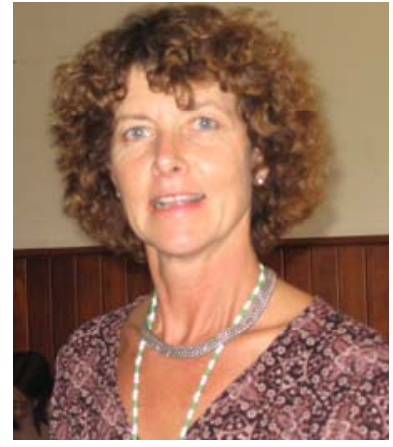

Elsje Scott is a Senior Lecturer at the Department of Information Systems, University of Cape Town. Her main research interest is systems development group projects which include knowledge areas like project management, people management and software engineering. Specific focus areas are software testing, object-oriented programming concepts, general issues concerning the development of efficient computer systems in Information Systems, assessment strategies and software standards. 